\title{
UTILIDAD DE LA CONTABILIDAD PARA EMPRENDEDORES NO OBLIGADOS A LLEVAR CONTABILIDAD
}

\section{USEFULNESS OF ACCOUNTING FOR ENTREPRENEURS NOT OBLIGATED TO KEEP ACCOUNTING}

\author{
Pablo Domingo Vilela Mera ${ }^{1}$ \\ Elizabeth Jacqueline Govea Robinzón ${ }^{2}$ \\ Gabriela Elizabeth Vilela Govea ${ }^{3}$
}

Recibido: 2019-08-21 / Revisado: 2019-10-01 / Aceptado: 2019-10-25 / Publicado: 2020-01-01

Forma sugerida de citar: Vilela-Mera, P. D., Govea-Robinzón, E. J. y Vilela-Govea, G. E. (2020). Utilidad de la Contabilidad para emprendedores no obligados a llevar contabilidad. Retos de la Ciencia. 4(8), pp. 55-75. https://doi.org/10.53877/rc.4.8.20200101.05

\section{RESUMEN}

El desarrollo económico, la globalización de la economía y las tecnologías de la información y comunicación provocaron que la contabilidad actualizara sus postulados con las Normas internacionales de información financiera, para estandarizar el registro, resumen y reporte de las operaciones económicas de las empresas, con el objeto de facilitar su análisis e interpretación. Estos hechos impulsaron la creación de pequeños negocios en todo el orbe como trabajo autónomo ante las pocas plazas que genera la automatización de la producción de bienes y servicios, los que en su mayoría son emprendimientos de personas naturales, que lo hacen a diario con poco capital de sus ahorros, apoyo familiar o créditos bancarios a bajo interés. Esto incrementó la carga tributaria, requiriendo un mejor control contable de las transacciones para su pago. En el Ecuador los emprendedores que no están obligados a llevar contabilidad deben tener un libro de ingresos y egresos para tributar, lo que generó esta investigación, porque estos no tienen la preparación necesaria y su negocio no rinde para pagar un Contador. El objetivo de este trabajo fue capacitarlos para que hagan la contabilidad de sus operaciones con el diseño y aplicación de un libro diario columnario genérico de fácil utilización.

Palabras claves: contabilidad, emprendedor, negocio, resultado.

\footnotetext{
1 Doctor en Ciencias Contables y Financieras (PhD. Profesor Principal a Tiempo Completo en la Universidad Técnica “Luis Vargas Torres". Ecuador. E-mail: pd_vilela@hotmail.com

2 Doctor en Ciencias Contables y Financieras (PhD). Profesor Principal a Tiempo Completo en la Universidad Técnica "Luis Vargas Torres". Ecuador. E-mail: yaqui-63@hotmail.com

3 Magíster en Economía y Dirección de Empresas. Profesor Ocasional a Tiempo Completo en la Escuela Superior Politécnica del Litoral. Ecuador. E-mail: gababu_85@hotmail.com
} 


\section{ABSTRACT}

The development of the economy, globalization, and technologies of information and communication influenced accounting science to upgrade their postulates with the International Financial Reporting Standards (IFRS). Those new rules were made to unify the registration method, summarize and inform the companies' economic operations looking to improve its analysis and interpretation. Due to this, a lot of new businesses were created worldwide as independent jobs because of the few opportunities generated by the automation of the production of goods and services. Most of them were formed as people's entrepreneurs by using their daily savings, family support, or bank loans with low-interest rates. As consequence of more economic activities, the tax weight also increased and, thereby, better accounting control to determine the amount payable of every operation was required. In Ecuador, the entrepreneurs not required to bookkeeping must have daily control of incomes and expenses to establish their taxes, which is the reason for doing this investigation, mainly because they don't have the academic studies nor enough profit to afford accountant's wage. The main purpose of this work was to train them to keep accounting by themselves in which they can control their activities through designing and applicating an easy-to-use generic columnar journal.

Keywords: accounting, entrepreneur, business, results.

\section{INTRODUCCIÓN}

Partiendo del hecho de que todo negocio por muy pequeño que sea debe tener una contabilidad para registrar y resumir sus bienes y deudas de manera periódica, para conocer el estado económico de sus actividades que le permita a sus dueños tomar decisiones con sus resultados, sean estos favorables o desfavorables.

La contabilidad es una herramienta valiosa para el control económico de toda actividad económica de bienes o servicios en una sociedad, porque permite registrar y resumir sus operaciones, las mismas que pueden ser de una persona natural, jurídica o de un grupo de éstas, que operan en todos los países; se la organiza para apoyar la administración de los recursos, tales como: dineros, bienes, materiales y personas.

Actualmente es muy importante en todo tipo de negocio, sea este: extractivo, productivo, comercial o servicio que realice un emprendedor, microempresario, pequeña empresa, mediana empresa o grande empresa; lo que permite su administración eficiente, para decidir la ejecución de una acción o inversión, como el manejo del dinero por cobros y pagos, compras y ventas, producción, ahorros y sobre todo egresos operacionales y tributarios.

Vista así, la contabilidad permite mantener bajo control todos los asuntos económicos en estos negocios, ejecutando y registrando sus operaciones dentro del marco legal vigente, archivando la documentación sustentatoria y emitiendo sus resultados en estados financieros de acuerdo con las normas de contabilidad vigente.

En el Ecuador, los negocios de las personas naturales en relación con la contabilidad están normados por el Servicio de Rentas Internas (SRI), que indica, que las personas naturales no obligadas a llevar contabilidad, son todas las personas naturales nacionales o extranjeras que realizan actividades económicas lícitas en el país, las mismas que están obligadas a inscribirse en el Registro Único del Contribuyente (RUC), emitir y entregar comprobantes o notas de ventas autorizados 
por el SRI por todas sus transacciones y presentar declaraciones de impuestos de acuerdo a su actividad económica; estas personas pueden ser profesionales, comisionistas, artesanos, y demás trabajadores autónomos (sin título profesional y no empresarios), los que además deberán llevar un registro de sus ingresos y egresos. (KVM, 2020)

La obligatoriedad de las leyes de que estas personas deben cumplir con las disposiciones anteriores; representa un problema para los emprendedores, porque muchos de ellos no tienen una preparación formal para realizarlo y por las características de sus negocios no tienen los recursos suficientes para asesorarse de un contador profesional.

En el país de acuerdo al volumen anual de ventas y al número de personas ocupadas, el Instituto Nacional de Estadísticas y Censos (INEC) define a las empresas por su tamaño, según los resultados del último censo del 2012, el emprendimiento y surgimiento de pequeños negocios es una característica del sector empresarial, el mismo que de las 704.556 empresas registradas, 631.430 eran microempresas que representaban casi el $90 \%$, indicador que se mantiene actualmente; por lo tanto, la mayoría de estos negocios no están obligados a llevar contabilidad. (Ordóñez, 2012)

Ante esta problemática, el autor considera que es importante sugerir al emprendedor su capacitación, como objetivo de esta investigación, para que realice el registro cronológico de todas las operaciones económicas de su negocio, en un libro diario sencillo diseñado para el efecto, para conocer sus resultados en estados financieros básicos, que le permita tomar decisiones acertadas y de beneficio para su negocio, puesto que un emprendedor es una persona que realiza pequeños negocios con poco capital que financia a corto plazo.

\section{Para profundizar la investigación fue necesario analizar:}

- El papel del emprendedor, para reconocer los elementos más importantes de sus actividades.

- La función de la contabilidad, para conocer los fundamentos, elementos y proceso básico.

- La importancia de los documentos fuentes, para elaborar y reconocer los documentos que sustentan las transacciones económicas.

- El libro diario columnario, para registrar, resumir y revelar los resultados de las operaciones económicas

Además, se investigó la documentación y los emprendedores existentes en la localidad, contrastándola con las experiencias del ejercicio profesional en este campo, como negocios, empresas y entidades en las que los autores han tenido la oportunidad de conocer y laborar; empleando los métodos empíricos de investigación científica para describir y explicar la realidad, así como para recabar, resumir e interpretar sus resultados.

\section{FUNDAMENTACIÓN}

\section{El Emprendedor}

Breves antecedentes. El emprendimiento tiene su origen en el inicio de la humanidad, porque el hombre a través del tiempo ha luchado para sobrevivir, perfeccionar las maneras de hacer sus actividades y mejorar su calidad de vida; como 
elementos innatos de su desarrollo y alcance de objetivos para su realización personal, no obstante, muchas personas no han desarrollado las habilidades emprendedoras, marcando la diferencia entre los seres humanos creativos y no creativos, porque muchos hombres y mujeres que han ideado algún emprendimientos se convirtieron en prominentes empresarios que lograron el desarrollo de las mayoría de los países del mundo, aportando así con el sorprendente progreso de la sociedad, actividad que actualmente se conoce como el "espíritu emprendedor" de los individuos de una comunidad. (Aguirre, 2017)

Definición. Emprendedor es un término que tiene muchas acepciones, de acuerdo en el contexto que se lo aplique, tales como:

- Fernando Trías de Bes (2020), es "Emprender es una forma de enfrentarse al mundo, es una manera de entender la vida con la que no todo el mundo se siente a gusto. ¿Y cuál es esa forma de vida? Es aquella en la que la persona disfruta con la incertidumbre y la inseguridad de qué pasará mañana. El verdadero emprendedor es aquel a quien lo incierto le procura un especial placer"

- SLP (2015), es "El Emprendedor, ra. Persona que identifica una oportunidad de negocio y decide organizar los recursos necesarios para ponerla en marcha en su futura empresa"

- Rafael Alcaraz (2011), es "En el ámbito de los negocios el emprendedor es un empresario, es el propietario de una empresa comercial con fines de lucro".

Con las concepciones anteriores, se puede definir al emprendedor como la persona natural de una sociedad, que idea un negocio de oportunidad y lo pone en ejecución con poco capital que financia a corto plazo, para realizar actividades económicas y vivir de sus ganancias o rendimientos.

Características. El emprendedor es una persona que posee un alto grado de confianza en sí mismo y una serie de características que le permiten detectar oportunidades y generar ideas de negocio a partir de la creación, innovación y el empleo adecuado de sus recursos para lograr objetivos; asumiendo el riesgo inherente a la toma de decisiones, perseverando en la ejecución del proyecto, por esto se lo conoce como la persona que tiene una capacidad innata para hacer negocio y obtener ganancias en estas actividades; muchos estudiosos coinciden en que los emprendedores poseen una serie de características que los distinguen del resto de las personas, tales como: Motivacionales, Personales, Físicas, Intelectuales, y Generales. (Sánchez-Almagro, 2003)

Tipos. Por la importancia que tienen los emprendedores en el desarrollo económico de un país y considerando las características más importantes de las personalidades que éstos tienen, se los clasifica en: Administrativo, Oportunista, Adquisitivo, Incubado e Imitador, (Schollhammer, 1980)

Requerimientos. Un emprendedor exitoso de estos tiempos requiere cumplir con ciertos procesos para materializar una idea de negocio, para lo cual se necesita mucho carácter para lograrlo y sobre todo soportar las equivocaciones propias de estas actividades, aunque el mayor problema radica en hacer bien el negocio como trabajo propio; para lo cual, hay que ejecutar los siguientes procedimientos: (Zapata, 2018).

- Explorar, las necesidades que se tienen en el lugar donde se va a emprender, observando el mercado detenidamente y detectando lo que más requiere la comunidad para su satisfacción, así como mirar en viajes negocios que no existen en la localidad para implementarlos. 
- Tipo de negocio, a implementar se escoge luego de conocer los requerimientos de la ciudadanía, asegurando así que el negocio ideado sea el adecuado; para lo cual es necesario mostrar el bien o servicio a entregar, probándolo si es necesario, así como consultar el precio que el cliente estaría dispuesto a pagar. Plan de negocio, verbal o escrito de manera breve, claro y conciso con la información más importante del negocio, analizando detalladamente la idea y los recursos a necesitar, así como otros elementos necesarios, como la identificación de los obstáculos a enfrentar y las herramientas a requerir.

\section{La Contabilidad}

Breves reseña histórica. La contabilidad existe desde tiempos remotos, porque la comunidad utilizó números, escrituras y medios de cambio para las transacciones comerciales que se realizaban; tanto así que los banqueros griegos en Atenas eran muy influyentes en el imperio de Alejandro Magno; en el imperio romano los jefes de familia registraban los ingresos y egresos en un libro de contabilidad llamado "Codex o Tubulae"; aunque en 1494 en Italia Luca Pacioli creó la "partida doble", de la contabilidad que existe hasta hoy.

Esta disciplina desde sus inicios ha sido una herramienta para registrar las operaciones económicas de todo tipo negocio, pero en la revolución industrial la primera que se dio entre los años 1750 y 1840, y la segunda, entre 1880 y 1914 (Pérez y Garde 2012) cobró mayor importancia, por el auge económico y la necesidad de llevar un control riguroso de las transacciones. Actualmente la contabilidad ha evolucionado significativamente como consecuencia del crecimiento económico, la globalización de la economía y el desarrollo de las tecnologías de información y comunicación; por lo que sus procesos ya no se realizan a mano en libros de contabilidad, sino en programas de contabilidad computarizados.

La apertura económica de los últimos tiempos, favoreció el comercio y las inversiones en los diferentes países del mundo, lo que obligó a homologar las normas contables, para lo cual la International Accounting Standards Board (IASB) desarrolló los estándares internacionales de contabilidad a través las Normas Internacionales de Contabilidad (NIC) inicialmente y luego las Normas Internacionales de Información Financiera (NIIF) vigentes actualmente. (Acevedo, 2009)

Definición. A la contabilidad se la ha conceptualizado de muchas maneras de acuerdo a sus autores, tales como:

- Falconí, Altamirano y Avellán. (2018). "La contabilidad es la ciencia, el arte, la disciplina que permite registrar en forma ordenada y cronológica las operaciones en una empresa u organización para obtener información financiera que permitan tomar decisiones"

- Amat, O. (2016). "La contabilidad es una parte de la economía que se encarga de obtener información financiera interna y externa sobre las empresas para poder permitir su control y la adecuada toma de decisiones"

- Guajardo y Andrade (2008). "El propósito básico de la contabilidad es proveer información útil acerca de una entidad económica, para facilitar la toma de decisiones de sus diferentes usuarios (accionistas, acreedores, inversionistas potenciales, clientes, administradores, gobierno, etc.)."

Los conceptos anteriores, permiten definir a la contabilidad como la actividad que realiza una persona o un contador en un negocio, registrando las transacciones para controlar las operaciones económicas financieras en un período de tiempo 
determinado, revelando sus resultados en estados financieros, para la toma de decisiones de sus dueños.

Importancia. La contabilidad es importante porque todo negocio o empresa por muy pequeña que sea, tienen la necesidad de llevar un control cronológico de sus operaciones mercantiles, para con sus resultados tomar decisiones que le permita lograr un mayor rendimiento económico; además porque proporciona información relevante a dueños, gerentes, clientes, acreedores y trabajadores relacionados con sus bienes, valores y deudas.

\section{Clasificación. La contabilidad se clasifica básicamente en: (Nuño, 2018)}

- Industrial o de Costos, se utiliza en los negocios o empresas que transforman materias primas en productos elaborados para el consumo, como industrias, factorías, etc.

- Comercial o de Intermediación, se utiliza en los negocios o empresas que se dedican a comprar y vender productos elaborados sin cambios para el consumo, como almacenes, farmacias, etc.

- Servicio o de inmaterial, se utiliza en los negocios o empresas dedicadas a la prestación de servicios para satisfacer las necesidades sociales, como educación, informática, etc.

- Extractiva o de explotación. Se utiliza en los negocios o empresas dedicadas a usufructuar los recursos naturales, como minas, yacimientos, bosques primarios, etc.

Elementos. Para que la contabilidad de un negocio haga el control que se requiere, utiliza varios elementos que son:

Principio del devengado, es el método de contabilidad que permite registrar los ingresos o gastos en el periodo contable al que corresponde, a pesar de que tengan que ejecutarse de manera anticipada o diferida; por lo que los servicios o bienes utilizados o consumidos en el ejercicio, aunque no hayan sido cancelados se deben registrar formulando un asiento de ajuste; así se reconocen y se registran eventos o transacciones, como intereses por cobrar de préstamos concedido; remuneraciones vencidas pendientes de pago; provisiones, depreciación y amortizaciones de activos; etc. (Gavelán, 2000)

Principio de partida doble, es el fundamento contable de la dualidad económica que tiene toda transacción comercial de un negocio o empresa, en donde "a toda partida o cuenta registrada en él Debe (D) le corresponde otra partida o cuenta registrada en el Haber $(\mathrm{H})$ " o "No hay deudor sin acreedor, ni acreedor sin deudor"; esta duplicidad representa una igualdad entre las sumas del $\mathrm{D}$ y $\mathrm{H}$, lo que permite su comprobación. Con este principio, se observan los cambios en el Activo (A) en donde se aplican los fondos y en el Pasivo $(P)$ en donde se originan los fondos y los resultados en su Capital $(\mathrm{C})$; estas partes están relacionadas por la suma de las transacciones registradas sobre esta base. (Gavelán, 2000)

Cuenta contable, es el nombre que se le da a un grupo de bienes, valores o servicios que tienen las mismas características; medios con los que se subdivide el A, P y C, nominándolas y agrupándolas de acuerdo con su afinidad y tipo de negocio; por ejemplo: (Hernández, 2005)

- Dinero en efectivo se llama Caja.

- Deudas de terceros sin documentos se llama Cuentas por pagar.

- Cobro de servicios se llama Servicios ganados. 
- Pago de publicidad se llama Gastos de publicidad

Por la importancia que tienen las cuentas en identificar objetivamente los pormenores de una transacción comercial, se las puede clasificar en: (Hernández, 2005)

Cuentas permanentes, son las que representan los bienes, derecho y obligaciones de un negocio o empresa, que integran el activo, pasivo y capital o patrimonio; son permanentes porque constituyen lo que se posee y se debe, sus saldos se traspasas de un ejercicio a otro; y porque forman parte de Estado de situación financiero o Balance general.

Cuentas temporales, son las cuentas que están vigentes solo el tiempo que dura un ejercicio contable de un negocio, las mismas que al finalizarlo son cerradas y su resultado se traspasa al capital a través de la cuenta utilidad o la pérdida del ejercicio. Estas cuentas se crean en cada ejercicio económico para registrar los ingresos y los costos y gastos; que son los que al finalizar un ejercicio contable arrojan los resultados obtenidos, por lo que, se las conoce como cuenta de resultados.

Proceso. La contabilidad por la importancia que tienen en los negocios, se realiza con los siguientes procesos:

Análisis de transacciones, que se realiza descomponiendo los elementos de una transacción comercial para su registro, los mismos que son:

- Personas que intervienen (deudores o acreedores).

- Bien, Valor o Servicio que se intercambia (producto, título, ayuda).

- Documentos de respaldo (factura, contrato, nómina, planilla, acta, cheque, boucher, escritura, acción, bono, etc.)

- Medio de pago (dinero o especies)

Registro de transacciones, se realiza en un diario general, que es cuaderno de trabajo en el que se registran cronológicamente estas operaciones.

Resumen de transacciones registradas, se realiza escribiendo cronológicamente los valores registrados en el diario en cada una de las cuentas utilizadas, tanto los del debe como los del haber, lo que se conoce como mayorización.

Resultados del resumen de transacciones registradas, se realiza escribiendo los saldos que presentan cada una de las cuentas resumidas al final del ejercicio contable de un negocio, en los estados financieros que son: Estado de resultado, que presenta las utilidades o pérdidas del negocio comparando las cuentas de ingresos y gastos, y Estado de situación, que presenta la situación económica del negocio con las cuentas de activos, pasivos y capital.

Los documentos fuentes

Definición. Los documentos fuentes que se utilizan en la contabilidad de un negocio o empresa, tienen muchas definiciones, tales como:

- Definición. Org. (2020) "Es el justificante propio o ajeno que da origen a un asiento contable. Contiene, la información necesaria para el registro contable de una operación, y tiene la función de comprobar razonablemente la realidad de dicha operación"

- Falconí, Altamirano, y Avellán, (2018) "Son el respaldo de cada una de las operaciones económicas que se lleva a cabo dentro de un negocio."

Con los criterios anteriores, se puede definir que los documentos fuentes son los que soportan legalmente las transacciones económicas de un negocio o empresa en una comunidad, permitiendo registrarlas, resumirlas y reportar sus resultados. 
De allí la importancia de estos documentos, porque sin éstos no se podría hacer ningún tipo de registro contable.

Tipos. El desarrollo económico actual, exige cada día mayor cantidad de documentos comerciales en papeles o electrónicos, que garantices la legalidad de las transacciones económicas de los negocios en los diferentes países del mundo, por lo que, los tipos básicos de estos documentos son: Factura, Notas de venta, Ticket de máquina registradora, Cheque, Recibo, Letra de cambio, Pagaré y Rol de pago. (Definición. Org., 2020)

Usos y archivo. Los documentos fuentes de la contabilidad una vez emitidos con las transacciones económicas de los negocios o empresas, se utilizan en el registro cronológico de estas operaciones, en los libros de contabilidad en el momento en que se ejecutan; y de la misma manera para que no se extravíen, se deben archivar en el orden de los registros, de manera clara y precisa que garanticen la integridad y autenticidad de las operaciones. (Falconí, Altamirano, y Avellán, 2018)

\section{El libro diario columnario}

Definición. El libro diario columnario o libro diario mayor como también se lo llama, tiene definiciones, como:

- OIT, (2016). "El libro diario columnario es de mucha utilidad para los negocios pequeños para llevar registros de transacciones en efectivo, transacciones bancarias, ventas, costos y el impuesto al valor agregado"

- Rincón, (2015). "El libro diario columnario es un libro mayor donde se registran las cuentas de activos, pasivos y patrimonio de la cooperativa"

- María, (2013). "El libro diario columnario registra los comprobantes de diario o de resumen, cuando el proceso contable se hace manualmente.

Estas concepciones permiten definir que el libro diario columnario es un registro contable, que permite apuntar cronológicamente todas las transacciones económicas de negocios y empresas pequeñas, en columnas que resumen sus movimientos con facilidad para elaborar estados financieros con sus resultados.

Importancia. El libro diario columnario es importante porque permite no solo registrar cronológicamente las transacciones económicas de un negocio, sino también resumir cada una de sus columnas, conociendo así los saldos de las cuentas al final de un período o subperíodo contable, con las que se elaboran los estados financieros.

Diseño. El libro diario columnario que se utiliza en cualquier negocio, se realiza en un cuaderno columnario de contabilidad o en una hoja de Excel de un computador o una lapto, creando las columnas de las cuentas que sean necesarias para registrar las transacciones realizadas. (OIT, 2016)

\section{METODOLOGÍA}

Para ejecutar este trabajo se utilizaron los siguientes métodos de investigación científica: (Cabezas, Andrade, y Torres, 2018)

- Inductivo-Deductivo, para inducir y deducir los hechos de las actividades de los emprendedores desde su contexto a sus particularidades y viceversa, para que a partir de la bibliografía analizada trasladarse desde el conocimiento objeto de estudio a la comprensión de sus actividades productivas. 
- Histórico-Lógico, para investigar la historia, fundamentos, elementos y proceso de la contabilidad, para comprender los principios y condiciones en los que se desarrolla.

- Analítico-Sintético, para detallar los elementos relacionadas con el emprendimiento y la contabilidad, manifestados en el problema investigado.

- Cualitativo-Cuantitativo, para recolectar los datos relacionados con la contabilidad de los emprendedores con o sin medición numérica, ejecutar el análisis requerido e interpretar sus resultados.

Métodos que permitieron conocer la realidad del problema investigado, estableciendo las causas que provocan las dificultades y logrando proponer alternativa de solución.

La teorización de este problema se basó en la investigación bibliográfica documental, que es el proceso sistemático de recolección, selección, clasificación, evaluación y análisis de contenidos del material empírico impreso y gráfico, físico y/o virtual, que sirvió de fuente teórica de información conceptual y/o metodológica para este trabajo; lo que permitió conocer su realidad, estableciendo las causas principales que provocan los problemas y que proporcionan las destrezas para superarlos. (Rodríguez, 2013)

La recolección, procesamiento y análisis de la información se realizó considerando: primero, el objetivo de la investigación, que definieron los tipos de fuentes bibliográficas y documentales que se necesitaban; y segundo, las fuentes bibliográficas y documentales, se definieron y se clasificaron de acuerdo con los criterios de selección requeridos. Estos criterios fueron:

- De pertinencia, que las fuentes consultadas estuvieran en concordancia con el objetivo de la investigación, que aportaron conocimientos, enfoques, teorías, conceptos y/o experiencias significativas, para fundamentar el trabajo;

- De exhaustividad, que las fuentes consultadas fueran todas las posibles, necesarias y suficientes para fundamentar la investigación, sin excluirlas y permitiendo su enumeración y/o clasificación; $y$,

- De actualidad, que las fuentes consultadas fueran actuales para asegurar el reflejo de los últimos avances, los más recientes hallazgos y/o los antecedentes empíricos pertinentes, referidos a sucesos del pasado reciente o presente.

\section{RESULTADOS Y DISCUSIÓN}

Observando las actividades productivas de los emprendedores no obligados a llevar contabilidad, se logró diseñar y aplicar un libro diario columnario genérico, que les permitió realizar la contabilidad básica de sus transacciones económicas, basado en la teoría contable financiera, la experiencia de los autores y las particularidades de estos negocios; para lo cual, se visitó y capacitó un amplio sector de emprendedores de la ciudad, logrando así el objetivo de este trabajo. Se realizaron aplicaciones en negocios de compraventa, producción o elaboración y entrega de bienes y/o servicios, registrando las transacciones en el diario, resumiendo las cuentas y elaborando el estado de resultado y de situación correspondiente, con los que se pudieron tomar decisiones y declarar impuestos; a continuación, se presenta el ejemplo contable de un emprendedor de compra-venta de accesorios de celulares. (Ver tablas 1, 2, y 3) 
Presentado los resultados del trabajo y considerando que se trata de un proceso contable sencillo en un diario mayor de cuentas, es necesario discutirlo con otros estudios relacionados, pese a que no existen muchos al respecto; por lo que, se pretendió analizar la información más relevante que se conoce. En la aplicación de esta herramienta contable, se observó que los emprendedores no podían utilizarla adecuadamente en sus negocios por sus bajos niveles de educación, la complejidad de los fundamentos contables y la diversidad de sus transacciones; lo que solo, adiestrándolos se pudo lograr con algún grado de dificultad. El trabajo que más se ajusta al proceso contable planteado, es el de la OIT (2016) en su libro Mejore su negocio. Registros contables; que plantea procedimientos similares en un libro básico de registro contable, pero que no agrupa ni crea todas las cuentas necesarias para registrar las operaciones aplicando el principio de partida doble; por lo que su metodología difiere mucho con el diario columnario genérico utilizado en esta investigación.

\section{Tabla 1}

Diseño y aplicación de libro diario columnario genérico (En dólares americanos)

\begin{tabular}{|c|c|c|c|c|c|}
\hline \multirow{2}{*}{ Fecha } & \multirow{2}{*}{$\begin{array}{c}\text { Documento } \\
\text { No. }\end{array}$} & \multirow{2}{*}{ Detalle } & \multicolumn{3}{|c|}{ Caja } \\
\hline & & & D. & H. & S. \\
\hline $2 / 1 / 20$ & D. 1036578 & $\begin{array}{l}\text { Depósto banco } \\
\text { de capital inicial }\end{array}$ & & & \\
\hline $2 / 1 / 20$ & F. 678890 & $\begin{array}{l}\text { Pago con } \\
\text { cheque de } \\
\text { arriendo de } \\
\text { local de enero } \\
2020\end{array}$ & & & \\
\hline $5 / 1 / 20$ & F. 324567 & $\begin{array}{l}\text { Compra con } \\
\text { cheque de } \\
\text { varios } \\
\text { accesorios de } \\
\text { celeulares para } \\
\text { la venta }\end{array}$ & & & \\
\hline $5 / 1 / 20$ & NV. 235678 & $\begin{array}{l}\text { Compra con } \\
\text { cheque de } \\
\text { materiales de } \\
\text { despacho }\end{array}$ & & & \\
\hline $10 / 1 / 20$ & NV. 283540 & $\begin{array}{l}\text { Venta en } \\
\text { efectivo de } \\
\text { accesorios de } \\
\text { celulares }\end{array}$ & 400,00 & & 400,00 \\
\hline $10 / 1 / 20$ & NV. 283540 & $\begin{array}{l}\text { Costo de venta } \\
\text { de accesorios } \\
\text { de celulares } \\
\text { vendidos }\end{array}$ & & & \\
\hline
\end{tabular}


Tabla 1

Diseño y aplicación de libro diario columnario genérico (En dólares americanos)

\begin{tabular}{|c|c|c|c|c|c|}
\hline \multirow[t]{2}{*}{ Fecha } & \multirow{2}{*}{$\begin{array}{l}\text { Documento } \\
\text { No. }\end{array}$} & \multirow[t]{2}{*}{ Detalle } & \multicolumn{3}{|c|}{ Caja } \\
\hline & & & & H. & S. \\
\hline $11 / 1 / 20$ & D. 456839 & Depósito en efectivo & & 400,00 & 0.00 \\
\hline $15 / 1 / 20$ & F. 678905 & $\begin{array}{l}\text { Compra con cheque de } \\
\text { varios accesorios de } \\
\text { celeulares para la venta }\end{array}$ & & & \\
\hline $20 / 1 / 20$ & F. 335588 & $\begin{array}{l}\text { Compra con cheque de } \\
\text { una vitrina }\end{array}$ & & & \\
\hline $25 / 1 / 20$ & NV. 283541 & $\begin{array}{l}\text { Venta de accesorios de } \\
\text { celulares }\end{array}$ & 400,00 & & 400,00 \\
\hline $25 / 1 / 20$ & NV. 283541 & $\begin{array}{l}\text { Costo de venta de } \\
\text { accesorios de celulares } \\
\text { vendidos }\end{array}$ & & & \\
\hline $26 / 1 / 20$ & D. 284859 & Depósito en efectivo & & 400,00 & 0.00 \\
\hline $30 / 1 / 20$ & F. 154575 & $\begin{array}{l}\text { Pago servivo de agua } \\
\text { potable de enero } 2020\end{array}$ & & & \\
\hline $30 / 1 / 20$ & F. 252525 & $\begin{array}{l}\text { Pago servivo de energía } \\
\text { eléctrica de enero } 2020\end{array}$ & & & \\
\hline $30 / 1 / 20$ & F. 504575 & $\begin{array}{l}\text { Pago servivo de } \\
\text { telefónico de enero } 2020 \\
\text { Ajuste depreciación de la }\end{array}$ & & & \\
\hline $31 / 1 / 20$ & A. 1 & $\begin{array}{l}\text { vitrina al } 10 \% \text { anual por } \\
10 \text { días }\end{array}$ & & & \\
\hline \multicolumn{3}{|c|}{ Suman y Pasan } & 800,00 & 800,00 & 0.00 \\
\hline
\end{tabular}

Tabla 1

Diseño y aplicación de libro diario columnario genérico (En dólares americanos)

\begin{tabular}{llllll}
\hline Fecha & $\begin{array}{c}\text { Documento } \\
\text { No. }\end{array}$ & \multicolumn{1}{c}{ Detalle } & \multicolumn{3}{c}{ Banco } \\
\hline $2 / 1 / 20$ & D. 1036578 & $\begin{array}{l}\text { Depósto banco de } \\
\text { capital inicial } \\
\text { Pago con cheque de } \\
\text { arriendo de local de } \\
\text { enero 2020 }\end{array}$ & H. & S. \\
\hline 2/1/20 & F. 678890,00 & 112,00 & 380,00 \\
$5 / 1 / 20$ & F. 324567 & $\begin{array}{l}\text { Compra con cheque de } \\
\text { varios accesorios de } \\
\text { celeulares para la venta } \\
\text { Compra con cheque de }\end{array}$ & 224,00 & 164,00 \\
$5 / 1 / 20$ & NV. 235678 & $\begin{array}{l}\text { Comateriales de despacho } \\
\text { mater }\end{array}$ & 40,00 & 124,00
\end{tabular}


10/1/20 NV. 283540 Venta en efectivo de accesorios de celulares

Costo de venta de

10/1/20 NV. 283540 accesorios de celulares vendidos

11/1/20 $\quad$ D. 456839 Depósito en efectivo 400,00 524,00 Compra con cheque de

15/1/20 F. 678905 varios accesorios de celeulares para la venta

20/1/20 F. 335588

Compra con cheque de una vitrina

25/1/20 NV. 283541

Venta de accesorios de celulares

Costo de venta de

25/1/20 NV. 283541 accesorios de celulares vendidos

Tabla 1

Diseño y aplicación de libro diario columnario genérico (En dólares americanos)

Fecha Documento
No.

$26 / 1 / 20$

D. 284859

$30 / 1 / 20$

F. 154575

F. 252525

$30 / 1 / 20$
$30 / 1 / 20$

F. 504575

Detalle

D.

400,00

Dósito en efectivo

Pago servivo de agua

potable de enero 2020

Pago servivo de

energía eléctrica de

enero 2020

Pago servivo de

telefónico de enero

2020

Ajuste depreciación de

$31 / 1 / 20$ A. 1

la vitrina al $10 \%$ anual por 10 días

\section{Banco}

H.

S. 634,40

$10,00 \quad 624,40$

$25,00 \quad 599,40$

$20,00 \quad 579,40$

por 10 dias

Suman y Pasan

$1.300,00$

720,60

579,40

Tabla 1

Diseño y aplicación de libro diario columnario genérico (En dólares americanos)

\begin{tabular}{lllll}
\hline Fecha & $\begin{array}{c}\text { Documento } \\
\text { No. }\end{array}$ & \multicolumn{1}{c}{ Detalle } & \multicolumn{2}{c}{ Cuentas y Documentos por } \\
cobrar \\
2/1/20 & D. 1036578 & $\begin{array}{l}\text { Depósto banco de } \\
\text { capital inicial }\end{array}$ & D. & S. \\
\hline
\end{tabular}




\begin{tabular}{|c|c|c|}
\hline $2 / 1 / 20$ & F. 678890 & $\begin{array}{l}\text { Pago con cheque de } \\
\text { arriendo de local de } \\
\text { enero } 2020\end{array}$ \\
\hline $1 / 20$ & F. 324567 & $\begin{array}{l}\text { Compra con cheque de } \\
\text { varios accesorios de } \\
\text { celeulares para la venta }\end{array}$ \\
\hline 1 & NV. 235678 & $\begin{array}{l}\text { Compra con cheque de } \\
\text { materiales de despacho }\end{array}$ \\
\hline
\end{tabular}

Tabla 1

Diseño y aplicación de libro diario columnario genérico (En dólares americanos)

\begin{tabular}{|c|c|c|c|c|c|}
\hline \multirow[t]{2}{*}{ Fecha } & \multirow{2}{*}{$\begin{array}{l}\text { Documento } \\
\text { No. }\end{array}$} & \multirow[t]{2}{*}{ Detalle } & \multicolumn{3}{|c|}{$\begin{array}{c}\text { Cuentas y Documentos por } \\
\text { cobrar }\end{array}$} \\
\hline & & & D. & H. & S. \\
\hline $10 / 1 / 20$ & NV. 283540 & $\begin{array}{l}\text { Venta en efectivo de } \\
\text { accesorios de celulares } \\
\text { Costo de venta de }\end{array}$ & & & \\
\hline $10 / 1 / 20$ & NV. 283540 & $\begin{array}{l}\text { accesorios de celulares } \\
\text { vendidos }\end{array}$ & & & \\
\hline $11 / 1 / 20$ & D. 456839 & Depósito en efectivo & & & \\
\hline $15 / 1 / 20$ & F. 678905 & $\begin{array}{l}\text { Compra con cheque de } \\
\text { varios accesorios de } \\
\text { celeulares para la venta }\end{array}$ & & & \\
\hline $20 / 1 / 20$ & F. 335588 & $\begin{array}{l}\text { Compra con cheque de } \\
\text { una vitrina }\end{array}$ & & & \\
\hline $25 / 1 / 20$ & NV. 283541 & $\begin{array}{l}\text { Venta de accesorios de } \\
\text { celulares }\end{array}$ & 200,00 & & 200,00 \\
\hline $25 / 1 / 20$ & NV. 283541 & $\begin{array}{l}\text { Costo de venta de } \\
\text { accesorios de celulares } \\
\text { vendidos }\end{array}$ & & & \\
\hline $26 / 1 / 20$ & D. 284859 & Depósito en efectivo & & & \\
\hline $30 / 1 / 20$ & F. 154575 & $\begin{array}{l}\text { Pago servivo de agua } \\
\text { potable de enero } 2020\end{array}$ & & & \\
\hline $30 / 1 / 20$ & F. 252525 & $\begin{array}{l}\text { Pago servivo de } \\
\text { energía eléctrica de } \\
\text { enero } 2020\end{array}$ & & & \\
\hline $30 / 1 / 20$ & F. 504575 & $\begin{array}{l}\text { Pago servivo de } \\
\text { telefónico de enero } \\
2020\end{array}$ & & & \\
\hline
\end{tabular}

Tabla 1

Diseño y aplicación de libro diario columnario genérico (En dólares americanos)

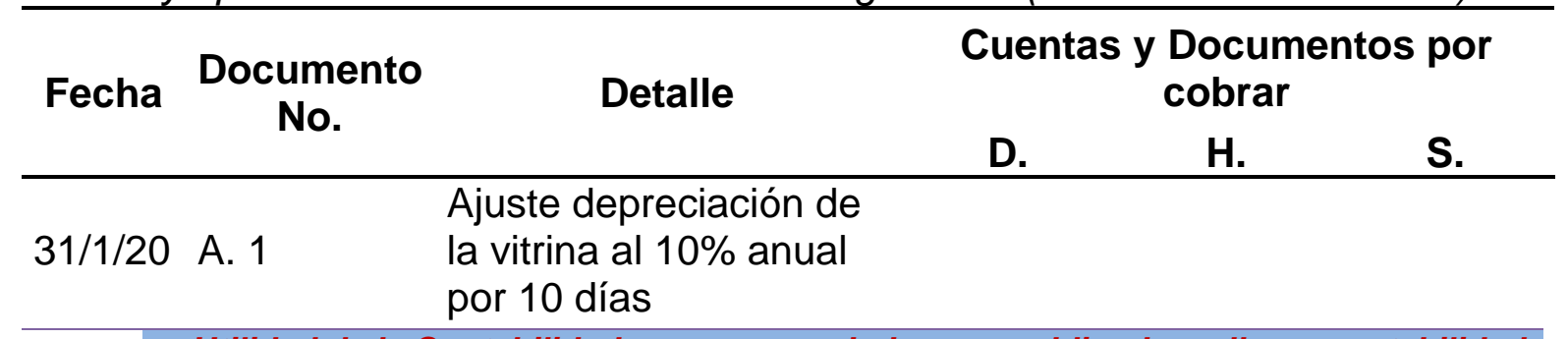




\section{Suman y Pasan}

200,00

0.00

200,00

Tabla 1

Diseño y aplicación de libro diario columnario genérico (En dólares americanos)

\begin{tabular}{|c|c|c|c|c|c|c|}
\hline \multirow[t]{2}{*}{ Fecha } & \multirow{2}{*}{$\begin{array}{c}\text { Documento } \\
\text { No. }\end{array}$} & \multirow[t]{2}{*}{ Detalle } & \multirow{2}{*}{$\begin{array}{c}\text { IVA } \\
\text { pagado }\end{array}$} & \multicolumn{3}{|c|}{$\begin{array}{c}\text { Inventario de Mercancías y } \\
\text { Materiales }\end{array}$} \\
\hline & & & & D. & H. & S. \\
\hline $2 / 1 / 20$ & D. 1036578 & $\begin{array}{l}\text { Depósto banco de } \\
\text { capital inicial }\end{array}$ & & & & \\
\hline $2 / 1 / 20$ & F. 678890 & $\begin{array}{l}\text { Pago con cheque de } \\
\text { arriendo de local de } \\
\text { enero } 2020\end{array}$ & 12,00 & & & \\
\hline $5 / 1 / 20$ & F. 324567 & $\begin{array}{l}\text { Compra con cheque de } \\
\text { varios accesorios de } \\
\text { celeulares para la venta }\end{array}$ & 24,00 & 200,00 & & 200,00 \\
\hline $5 / 1 / 20$ & NV. 235678 & $\begin{array}{l}\text { Compra con cheque de } \\
\text { materiales de despacho }\end{array}$ & & & & \\
\hline $10 / 1 / 20$ & NV. 283540 & $\begin{array}{l}\text { Venta en efectivo de } \\
\text { accesorios de celulares } \\
\text { Costo de venta de }\end{array}$ & & & & \\
\hline $10 / 1 / 20$ & NV. 283540 & $\begin{array}{l}\text { accesorios de celulares } \\
\text { vendidos }\end{array}$ & & & 200,00 & 0.00 \\
\hline $11 / 1 / 20$ & D. 456839 & Depósito en efectivo & & & & \\
\hline
\end{tabular}

Tabla 1

Diseño y aplicación de libro diario columnario genérico (En dólares americanos)

\begin{tabular}{|c|c|c|c|c|c|c|}
\hline \multirow[t]{2}{*}{ Fecha } & \multirow{2}{*}{$\begin{array}{l}\text { Documento } \\
\text { No. }\end{array}$} & \multirow[t]{2}{*}{ Detalle } & \multirow{2}{*}{$\begin{array}{l}\text { IVA } \\
\text { pagado }\end{array}$} & \multicolumn{3}{|c|}{$\begin{array}{c}\text { Inventario de Mercancías y } \\
\text { Materiales }\end{array}$} \\
\hline & & & & D. & H. & S. \\
\hline $15 / 1 / 20$ & F. 678905 & $\begin{array}{l}\text { Compra con cheque de } \\
\text { varios accesorios de } \\
\text { celeulares para la venta }\end{array}$ & 48,00 & 400,00 & & 400,00 \\
\hline $20 / 1 / 20$ & F. 335588 & $\begin{array}{l}\text { Compra con cheque de } \\
\text { una vitrina }\end{array}$ & 9,60 & & & \\
\hline $25 / 1 / 20$ & NV. 283541 & $\begin{array}{l}\text { Venta de accesorios de } \\
\text { celulares }\end{array}$ & & & & \\
\hline $25 / 1 / 20$ & NV. 283541 & $\begin{array}{l}\text { Costo de venta de } \\
\text { accesorios de celulares } \\
\text { vendidos }\end{array}$ & & & 300,00 & 100,00 \\
\hline $26 / 1 / 20$ & D. 284859 & Depósito en efectivo & & & & \\
\hline $30 / 1 / 20$ & F. 154575 & $\begin{array}{l}\text { Pago servivo de agua } \\
\text { potable de enero } 2020\end{array}$ & & & & \\
\hline
\end{tabular}




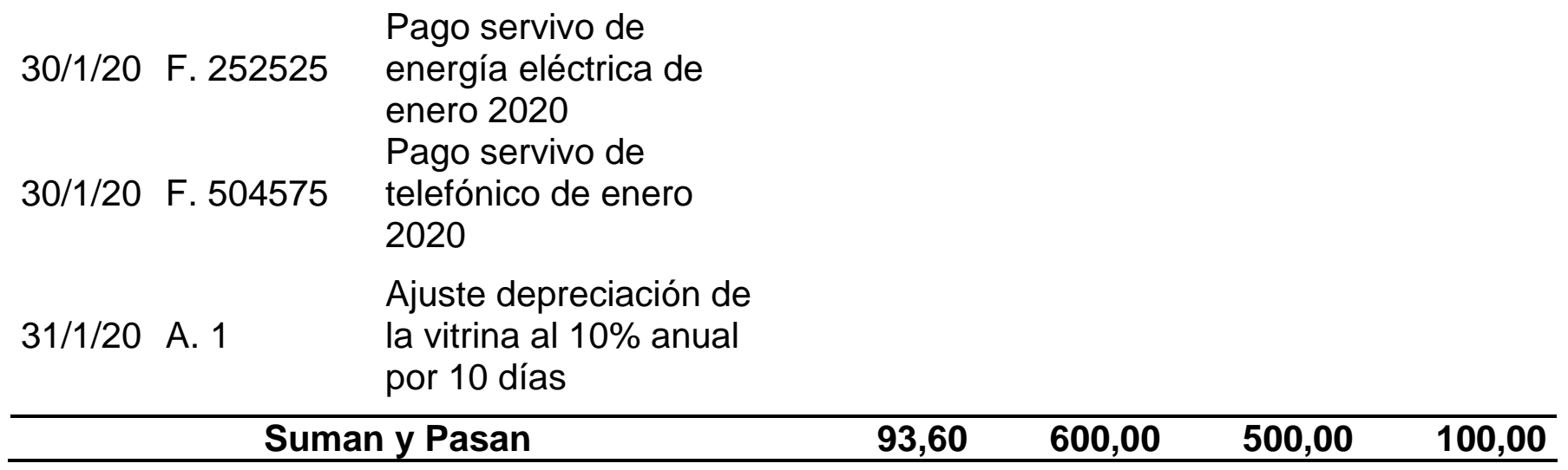

Tabla 1

Diseño y aplicación de libro diario columnario genérico (En dólares americanos)

\begin{tabular}{|c|c|c|c|c|c|}
\hline \multirow[t]{2}{*}{ Fecha } & \multirow{2}{*}{$\begin{array}{l}\text { Documento } \\
\text { No. }\end{array}$} & \multirow[t]{2}{*}{ Detalle } & \multicolumn{3}{|c|}{ Activos fijos } \\
\hline & & & D. & $\mathrm{H}$. & S. \\
\hline $2 / 1 / 20$ & D. 1036578 & $\begin{array}{l}\text { Depósto banco de } \\
\text { capital inicial }\end{array}$ & & & \\
\hline $2 / 1 / 20$ & F. 678890 & $\begin{array}{l}\text { Pago con cheque de } \\
\text { arriendo de local de } \\
\text { enero } 2020\end{array}$ & & & \\
\hline $5 / 1 / 20$ & F. 324567 & $\begin{array}{l}\text { Compra con cheque de } \\
\text { varios accesorios de } \\
\text { celeulares para la venta }\end{array}$ & & & \\
\hline $5 / 1 / 20$ & NV. 235678 & $\begin{array}{l}\text { Compra con cheque de } \\
\text { materiales de despacho }\end{array}$ & & & \\
\hline $10 / 1 / 20$ & NV. 283540 & $\begin{array}{l}\text { Venta en efectivo de } \\
\text { accesorios de celulares } \\
\text { Costo de venta de }\end{array}$ & & & \\
\hline $10 / 1 / 20$ & NV. 283540 & $\begin{array}{l}\text { accesorios de celulares } \\
\text { vendidos }\end{array}$ & & & \\
\hline $11 / 1 / 20$ & D. 456839 & $\begin{array}{l}\text { Depósito en efectivo } \\
\text { Compra con cheque de }\end{array}$ & & & \\
\hline $15 / 1 / 20$ & F. 678905 & $\begin{array}{l}\text { varios accesorios de } \\
\text { celeulares para la venta }\end{array}$ & & & \\
\hline $20 / 1 / 20$ & F. 335588 & $\begin{array}{l}\text { Compra con cheque de } \\
\text { una vitrina }\end{array}$ & 80,00 & & 80,00 \\
\hline $25 / 1 / 20$ & NV. 283541 & $\begin{array}{l}\text { Venta de accesorios de } \\
\text { celulares }\end{array}$ & & & \\
\hline $25 / 1 / 20$ & NV. 283541 & $\begin{array}{l}\text { Costo de venta de } \\
\text { accesorios de celulares } \\
\text { vendidos }\end{array}$ & & & \\
\hline
\end{tabular}

Tabla 1

Diseño y aplicación de libro diario columnario genérico (En dólares americanos) 


\begin{tabular}{|c|c|c|c|c|c|}
\hline \multirow{2}{*}{ Fecha } & \multirow{2}{*}{$\begin{array}{c}\text { Documento } \\
\text { No. }\end{array}$} & \multirow{2}{*}{ Detalle } & \multicolumn{3}{|c|}{ Activos fijos } \\
\hline & & & D. & H. & S. \\
\hline $26 / 1 / 20$ & D. 284859 & Depósito en efectivo & & & \\
\hline $30 / 1 / 20$ & F. 154575 & $\begin{array}{l}\text { Pago servivo de agua } \\
\text { potable de enero } 2020 \\
\text { Pago servivo de }\end{array}$ & & & \\
\hline $30 / 1 / 20$ & F. 252525 & $\begin{array}{l}\text { energía eléctrica de } \\
\text { enero } 2020 \\
\text { Pan }\end{array}$ & & & \\
\hline $30 / 1 / 20$ & F. 504575 & $\begin{array}{l}\text { Pago servivo de } \\
\text { telefónico de enero } \\
2020 \\
\text { Ajuste depreciación de }\end{array}$ & & & \\
\hline $31 / 1 / 20$ & A. 1 & $\begin{array}{l}\text { la vitrina al } 10 \% \text { anual } \\
\text { por } 10 \text { días }\end{array}$ & & 0,22 & 79,78 \\
\hline \multicolumn{3}{|c|}{ Suman y Pasan } & 80,00 & 0,22 & 79,78 \\
\hline
\end{tabular}

Tabla 1

Diseño y aplicación de libro diario columnario genérico (En dólares americanos)

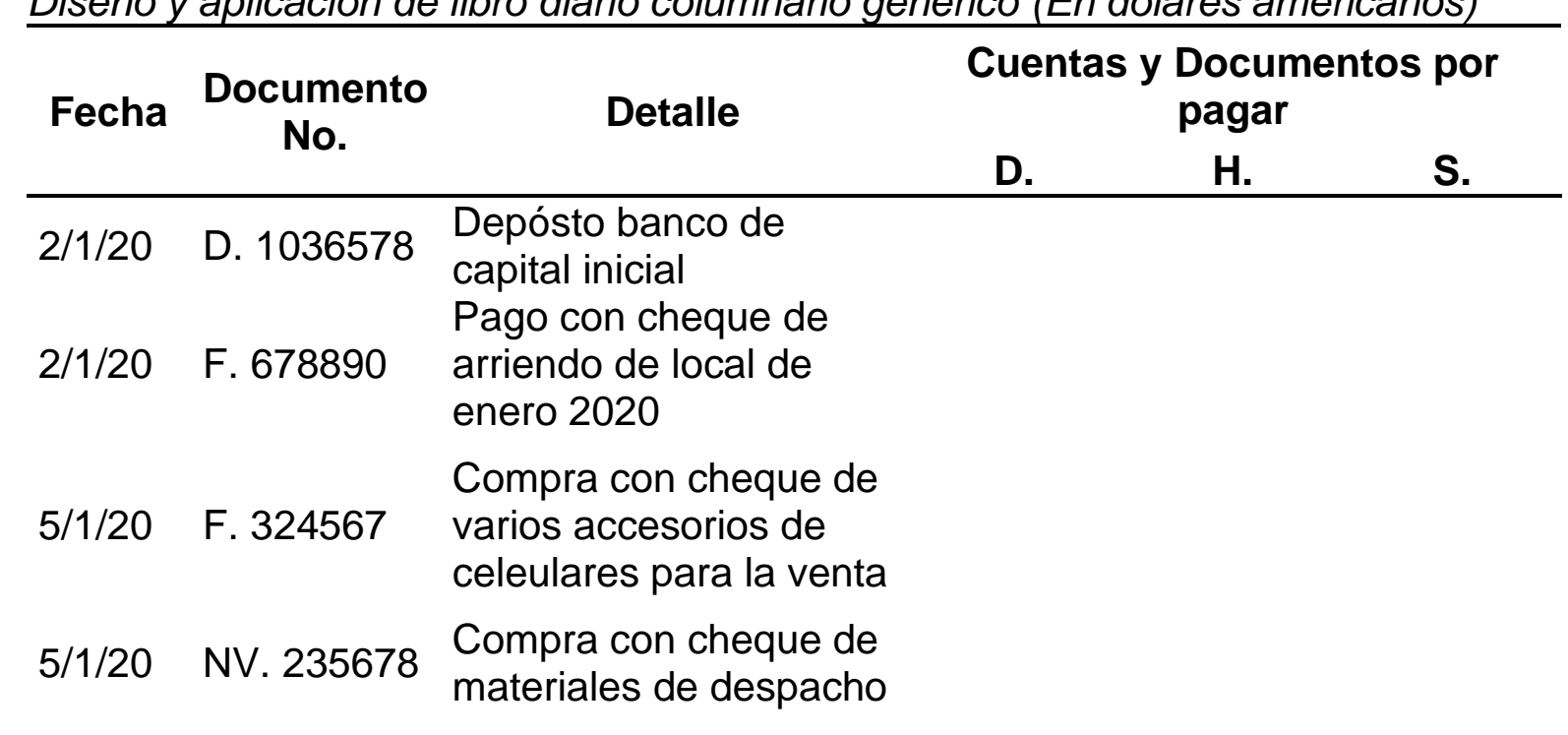

Tabla 1

Diseño y aplicación de libro diario columnario genérico (En dólares americanos)

\begin{tabular}{ccccc}
\hline \multirow{2}{*}{ Fecha } & $\begin{array}{c}\text { Documento } \\
\text { No. }\end{array}$ & Detalle & \multicolumn{3}{c}{ Cuentas y Documentos por } \\
& & Dagar & H. & S. \\
\hline
\end{tabular}

\begin{tabular}{ll}
\hline 10/1/20 NV. 283540 & $\begin{array}{l}\text { Venta en efectivo de } \\
\text { accesorios de celulares } \\
\text { Costo de venta de }\end{array}$ \\
10/1/20 NV. 283540 & $\begin{array}{l}\text { accesorios de celulares } \\
\text { vendidos }\end{array}$ \\
Depósito en efectivo
\end{tabular}




\begin{tabular}{|c|c|c|c|c|}
\hline $15 / 1 / 20$ & F. 678905 & $\begin{array}{l}\text { Compra con cheque de } \\
\text { varios accesorios de }\end{array}$ & 248,00 & 248,00 \\
\hline $20 / 1 / 20$ & F. 335588 & $\begin{array}{l}\text { Compra con cheque de } \\
\text { una vitrina }\end{array}$ & & \\
\hline $25 / 1 / 20$ & NV. 283541 & $\begin{array}{l}\text { Venta de accesorios de } \\
\text { celulares }\end{array}$ & & \\
\hline $25 / 1 / 20$ & NV. 283541 & $\begin{array}{l}\text { Costo de venta de } \\
\text { accesorios de celulares } \\
\text { vendidos }\end{array}$ & & \\
\hline $26 / 1 / 20$ & D. 284859 & Depósito en efectivo & & \\
\hline $30 / 1 / 20$ & F. 154575 & $\begin{array}{l}\text { Pago servivo de agua } \\
\text { potable de enero } 2020\end{array}$ & & \\
\hline $30 / 1 / 20$ & F. 252525 & $\begin{array}{l}\text { Pago servivo de } \\
\text { energía eléctrica de } \\
\text { enero } 2020\end{array}$ & & \\
\hline $30 / 1 / 20$ & F. 504575 & $\begin{array}{l}\text { Pago servivo de } \\
\text { telefónico de enero } \\
2020\end{array}$ & & \\
\hline
\end{tabular}

Tabla 1

Diseño y aplicación de libro diario columnario genérico (En dólares americanos)

\begin{tabular}{|c|c|c|c|c|c|}
\hline \multirow[t]{2}{*}{ Fecha } & \multirow{2}{*}{$\begin{array}{l}\text { Documento } \\
\text { No. }\end{array}$} & \multirow[t]{2}{*}{ Detalle } & \multicolumn{3}{|c|}{$\begin{array}{c}\text { Cuentas y Documentos por } \\
\text { pagar }\end{array}$} \\
\hline & & & D. & H. & S. \\
\hline $31 / 1 / 20$ & A. 1 & $\begin{array}{l}\text { Ajuste depreciación de } \\
\text { la vitrina al } 10 \% \text { anual } \\
\text { por } 10 \text { días }\end{array}$ & & & \\
\hline \multicolumn{3}{|c|}{ Suman y Pasan } & 0.00 & 248,00 & 248,00 \\
\hline
\end{tabular}

\section{Tabla 1}

Diseño y aplicación de libro diario columnario genérico (En dólares americanos)

\begin{tabular}{|c|c|c|c|c|c|c|}
\hline Fecha & $\begin{array}{c}\text { Documento } \\
\text { No. }\end{array}$ & Detalle & Capital & $\begin{array}{l}\text { Ventas e } \\
\text { Ingresos }\end{array}$ & $\begin{array}{l}\text { Costo de } \\
\text { venta }\end{array}$ & $\begin{array}{c}\text { Gastos } \\
\text { generales }\end{array}$ \\
\hline $2 / 1 / 20$ & D. 1036578 & $\begin{array}{l}\text { Depósto banco de } \\
\text { capital inicial }\end{array}$ & 500,00 & & & \\
\hline $2 / 1 / 20$ & F. 678890 & $\begin{array}{l}\text { Pago con cheque de } \\
\text { arriendo de local de } \\
\text { enero } 2020\end{array}$ & & & & 100,00 \\
\hline $5 / 1 / 20$ & F. 324567 & $\begin{array}{l}\text { Compra con cheque } \\
\text { de varios accesorios } \\
\text { de celeulares para la } \\
\text { venta }\end{array}$ & & & & \\
\hline $5 / 1 / 20$ & NV. 235678 & $\begin{array}{l}\text { Compra con cheque } \\
\text { de materiales de } \\
\text { despacho }\end{array}$ & & & & 40,00 \\
\hline
\end{tabular}




$\begin{array}{llll}\text { 10/1/20 NV. } 283540 & \begin{array}{l}\text { accesorios de } \\ \text { celulares } \\ \text { Costo de venta de }\end{array} & 400,00 & \\ 10 / 1 / 20 \text { NV. } 283540 & \begin{array}{l}\text { accesorios de } \\ \text { celulares vendidos }\end{array} & 200,00 \\ \text { Depósito en efectivo } & & \end{array}$

Tabla 1

Diseño y aplicación de libro diario columnario genérico (En dólares americanos)

\begin{tabular}{|c|c|c|c|c|}
\hline Fecha & $\begin{array}{l}\text { Documento } \\
\text { No. }\end{array}$ & Detalle & Capital & $\begin{array}{l}\text { Ventas e } \\
\text { Ingresos }\end{array}$ \\
\hline
\end{tabular}

\begin{tabular}{|c|c|c|c|c|c|c|}
\hline $15 / 1 / 20$ & F. 678905 & $\begin{array}{l}\text { Compra con cheque de } \\
\text { varios accesorios de } \\
\text { celeulares para la venta }\end{array}$ & & & & \\
\hline $20 / 1 / 20$ & F. 335588 & $\begin{array}{l}\text { Compra con cheque de } \\
\text { una vitrina }\end{array}$ & & & & \\
\hline $25 / 1 / 20$ & NV. 283541 & $\begin{array}{l}\text { Venta de accesorios de } \\
\text { celulares }\end{array}$ & & 600,00 & & \\
\hline $25 / 1 / 20$ & NV. 283541 & $\begin{array}{l}\text { Costo de venta de } \\
\text { accesorios de celulares } \\
\text { vendidos }\end{array}$ & & & 300,00 & \\
\hline $26 / 1 / 20$ & D. 284859 & Depósito en efectivo & & & & \\
\hline $30 / 1 / 20$ & F. 154575 & $\begin{array}{l}\text { Pago servivo de agua } \\
\text { potable de enero } 2020\end{array}$ & & & & 10,00 \\
\hline $30 / 1 / 20$ & F. 252525 & $\begin{array}{l}\text { energía eléctrica de } \\
\text { enero } 2020\end{array}$ & & & & 25,00 \\
\hline $30 / 1 / 20$ & F. 504575 & $\begin{array}{l}\text { Pago servivo de } \\
\text { telefónico de enero } \\
2020 \\
\text { Aiuste depreciación de }\end{array}$ & & & & 20,00 \\
\hline $31 / 1 / 20$ & A. 1 & $\begin{array}{l}\text { la vitrina al } 10 \% \text { anual } \\
\text { por } 10 \text { días }\end{array}$ & & & & 0,22 \\
\hline \multicolumn{3}{|c|}{ Suman y Pasan } & 500,00 & $1.000,00$ & 500,00 & 195,22 \\
\hline
\end{tabular}

Nota: Esta tabla muestra las operaciones realizadas en el formato del diario columnario del negocio del Sr. Fernando Manzano (Compra/Venta de accesorios de celular), Hoja No. 001

Fuente: Elaboración propia

\section{Tabla 2}

Estado de resultados (En dólares americanos)

INGRESOS:

Ventas e Ingresos

$1.000,00$

(-) Costo de venta $\underline{500,00}$ 
Utilidad bruta en venta

500,00

(-) Gastos operacionales:

Gastos generales

195,22

UTILIDAD NETA

304,78

Nota: Esta tabla muestra el Estado de Resultados del negocio del Sr. Fernando Manzano (Compra/Venta de accesorios de celular)

Fuente: Elaboración propia

\section{Tabla 3}

Estado de situación financiera (En dólares americanos)

ACTIVOS:

$1.052,78$

Activos Corrientes:

973,00

Bancos

579,40

Cuentas y documentos por Cobrar

200,00

IVA pagado

93,60

Inventario de mercancias y Materiales

100,00

Activos No corrientes:

79,78

Muebles y Enseres

80,00

(-) Depreciación Acumulada de Muebles y Enseres

79,78

PASIVOS:

248,00

Pasivos corrientes:

248,00

Cuentas y Documentos por pagar

248,00

PATRIMONIO:

804,78

Capital:

500,00

Aporte de capital

500,00

Resultado:

304,78

Utilidad neta

304,78

TOTAL DE PASIVOS MÁS PATRIMONIO

$1.052,78$

Nota: Esta tabla muestra el Estado de Situación Financiera del negocio del Sr. Fernando Manzano (Compra/Venta de accesorios de celular)

Fuente: Elaboración propia

\section{CONCLUSIONES}

La teoría contable actual, señala que todo negocio, empresa o entidad por muy pequeña que sea, debe llevar una contabilidad de sus transacciones económicas y financieras, para conocer el estado de sus bienes, deudas y el resultado sus actividades operacionales, que le permita a sus dueños tomar decisiones. 
En el Ecuador según el INEC el $90 \%$ de las empresas son microempresas de las cuales un alto porcentaje son pequeños negocios no obligados a llevar contabilidad; aunque de ellos no se conocen sus ventas y demás datos económicos, pero representan los emprendimientos que generan trabajo autónomo a un considerable grupo de la Población Económicamente Activa (PEA), lo que se observa en la mayoría de los países del mundo.

Según la legislación ecuatoriana las personas naturales no obligadas a llevar contabilidad, son todas las personas naturales nacionales o extranjeras que realizan actividades económicas lícitas, las mismas que están obligadas a inscribirse en el RUC, emitir y entregar notas de ventas autorizados por el SRI y presentar declaraciones de impuestos de acuerdo a sus actividades económicas, para lo cual deberán llevar un registro de sus ingresos y egresos.

Muchos de los emprendedores por ser personas naturales, no tienen una preparación formal para realizar la contabilidad de las transacciones comerciales de sus negocios, y por tratarse de pequeños negocios no cuentan con los recursos económicos para pagar el asesoramiento contable de un contador.

Los emprendedores son muy importantes en las actividades socioeconómicas de un país, por los rendimientos de sus negocios y las plazas de trabajo que generan, por lo que, deben llevar un mínimo control contable ajustados a los procesos actuales de esta disciplina, sustentado en los documentos fuentes que producen sus transacciones comerciales.

El registro de ingresos y egresos de los emprendedores en el Ecuador permitió con esta investigación el diseño y aplicación de un libro diario columnario genérico sencillo, que permite no solo cumplir esta exigencia legal, sino también resumir y revelar los resultados de todas las transacciones económicas de estos negocios.

\section{REFERENCIAS BIBLIOGRÁFICAS}

Acevedo, J. (2009). Breve Historia de la Contabilidad. Recuperado el 25 de marzo de 2020 de http://elcontadorvirtual.blogspot.com/2009/11/breve-historia-de-lacontabilidad.html

Aguirre, A. (2017). Cultura del emprendimiento. https://www.gerencie.com/cultura-delemprendimiento.html Recuperado el 24 de marzo de 2020

Amat, O. (2016). Contabilidad y finanzas para Dummies. Universitat Pompeu Fabra Libro proporcionado por el equipo Le Libros. Recuperado 3l 22 de mayo de 2020 de https://www.slideshare.net/isshinstark/contabilidad-y-finanzas-paradummies-oriol-amat

Cabezas, E., Andrade, D. y Torres, J. (2018). Introducción a la metodología de la investigación científica. Primera edición electrónica. Octubre de 2018. Universidad de las Fuerzas Armadas ESPE. ISBN: 978-9942-765-44-4. Ecuador. Recuperado el 25 de mayo de 2020 de http://repositorio.espe.edu.ec/jspui/bitstream/21000/15424/1//ntroduccion\%20 a\%20la\%20Metodologia\%20de\%20la\%20investigacion\%20cientifica.pdf

Definición. Org. (2020). Definición de documento fuente. Recuperado el 24 de mayo de 2020 de https://definicion.org/documento-fuente

Falconí, M. Altamirano, S y Avellán, N. (2018). La contabilidad y auditoría: ejes fundamentales para el control interno en las PYMES. Primera edición electrónica. Octubre de 2018 ISBN: 978-9942-765-25- Universidad de las Fuerzas Armadas ESPEC. Ecuador 
Gavelán, J. (2000). Principios de contabilidad generalmente aceptados. Vigencia y aplicación. Recuperado el 25 de marzo de 2020 de http://sisbib.unmsm.edu.pe/bibvirtual/publicaciones/quipukamayoc/2000/prime r/princi_conta.htm

Guajardo, G. y Andrade, N. (2008). Contabilidad financiera. Quinta edición. Instituto Tecnológico y de Estudios Superiores de Monterrey. McGrawHill/interamericana editores. México. ISBN-13: 978-970-10-6621-8.

Hernández, J. (2005). Cuentas contables, clasificación, concepto y descripción. Recuperado el 25 de marzo de 2020 de https://www.gestiopolis.com/cuentascontables-clasificacion-concepto-y-descripcion/

KVM. (2020). Personas naturales no obligadas y obligadas a llevar contabilidad en el Ecuador. Recuperado el 18 de mayo de 2020 de https://www.contadoresenquito.com/noticias-contadores-economia-trabajosauditorias-contable-empresas-quito-manabi-santo-domingoecuador. php?tablajb=noticias $\& p=76 \& t=$ Quienes-son-Personas-Naturales-noobligadas-a-llevar-contabilidad\&

María, R. (2013). Diario columnario mayor y balances. Recuperado el 24 de mayo de 2020 de http://procesosfinancieros.blogspot.com/2013/07/diario-columnariomayor-y-balances.html

Nuño, P. (2018). Clases de contabilidad. Recuperado el 25 de marzo de 2020 de https://www.emprendepyme.net/tipos-de-contabilidad.html

Oficina Internacional del Trabajo (OIT). (2016). Mejore su negocio. Registros contables. Primera edición 2016

Ordóñez, M. (2012). Una mirada estadística al Ecuador empresarial. Revista Gestión N²39. Página 21. Recuperado el 18 de mayo de 2010 de https://revistagestion.ec/sites/default/files/import/legacy_pdfs/239_005.pdf

Pérez, J. y Garde, A. (2012). Definición de revolución industrial. Recuperado el 22 de mayo de 2020 de https://definicion.de/revolucion-industrial/

Rincón, D. (2015). Diario columnario y 3 columnas. Recuperado el 24 de septiembre de 2020 de https://prezi.com/3k-9hbe0sv1z/diario-columnario-y-3-columnas/

Rodríguez, M. (2013). Investigación bibliográfica y documental. Recuperado de https://guiadetesis.wordpress.com/2013/08/19/acerca-de-la-investigacionbibliografica-y-documental/

Sánchez-Almagro, M. (2003). Perfil Psicológico del Autoempleado. Tesis doctoral no publicada, Universidad Complutense de Madrid, Madrid, España.

Schollhammer. (1980). Emprendedores. Recuperado el 21 de mayo de 2020 de https://www.clubensayos.com/Negocios/Emprendedores-Schollhammer-1980divide-a-los-emprendedores/3893602.html

SLP. (2015). Manual para la incubación de empresas de reciente creación. Sistema de financiamiento para el desarrollo. Recuperado el 10 de mayo de 2020 de https://sifide.gob.mx/wp-content/uploads/2018/03/manualincubacion.pdf

Trías de Bes, F. (2020). El Libro Negro del Emprendedor. 2da Edición. Recuperado el 19 de mayo de 2020 de https://soyemprendedor.co/wpcontent/uploads/2017/01/El-libro-negro-del-emprendedor-Fernando-

Tr\%C3\%ADas.pdf 